\title{
Effects of Supercharging Reagents on Noncovalent Complex Structure in Electrospray Ionization from Aqueous Solutions
}

\author{
Harry J. Sterling, ${ }^{a}$ Michael P. Daly, ${ }^{b}$ Geoffrey K. Feld, ${ }^{a}$ Katie L. Thoren, ${ }^{a}$ \\ Alexander F. Kintzer, ${ }^{a}$ Bryan A. Krantz, ${ }^{a}$ and Evan R. Williams ${ }^{a}$ \\ ${ }^{a}$ Department of Chemistry, University of California-Berkeley, Berkeley, California, USA \\ ${ }^{\mathrm{b}}$ Waters Corporation, Pleasanton, California, USA
}

\begin{abstract}
The effects of two supercharging reagents, $m$-nitrobenzyl alcohol ( $m$-NBA) and sulfolane, on the charge-state distributions and conformations of myoglobin ions formed by electrospray ionization were investigated. Addition of $0.4 \% \mathrm{~m}$-NBA to aqueous ammonium acetate solutions of myoglobin results in an increase in the maximum charge state from 9+ to 19+, and an increase in the average charge state from $7.9+$ to $11.7+$, compared with solutions without $m-\mathrm{NBA}$. The extent of supercharging with sulfolane on a per mole basis is lower than that with $m$-NBA, but comparable charging was obtained at higher concentration. Arrival time distributions obtained from traveling wave ion mobility spectrometry show that the higher charge state ions that are formed with these supercharging reagents are significantly more unfolded than lower charge state ions. Results from circular dichroism spectroscopy show that sulfolane can act as chemical denaturant, destabilizing myoglobin by $\sim 1.5 \mathrm{kcal} / \mathrm{mol} / \mathrm{M}$ at $25^{\circ} \mathrm{C}$. Because these supercharging reagents have low vapor pressures, aqueous droplets are preferentially enriched in these reagents as evaporation occurs. Less evaporative cooling will occur after the droplets are substantially enriched in the low volatility supercharging reagent, and the droplet temperature should be higher compared with when these reagents are not present. Protein unfolding induced by chemical and/or thermal denaturation in the electrospray droplet appears to be the primary origin of the enhanced charging observed for noncovalent protein complexes formed from aqueous solutions that contain these supercharging reagents, although other factors almost certainly influence the extent of charging as well. (J Am Soc Mass Spectrom 2010, 21, 1762-1774) ( 2010 Published by Elsevier Inc. on behalf of American Society for Mass Spectrometry
\end{abstract}

W ith electrospray ionization (ESI), gaseous multiply charged molecules can be formed directly from solution, which is a significant advantage for the analysis and structural characterization of large molecules and noncovalent complexes by mass spectrometry (MS). Multiple charging results in $m / z$ ratios of large molecules that are typically within a range where the performance of most mass spectrometers excel, making it possible to measure masses of large molecules with virtually any type of mass spectrometer. Multiply charged ions can often be more readily fragmented in tandem MS experiments aimed at structural characterization, such as peptide or protein sequencing [1], and higher charge state ions can be more readily detected in some mass spectrometers, such as the Orbitrap and Fourier-transform ion cyclotron resonance (FT/ICR) instruments, where the ion signal is directly proportional to charge $[2,3]$. The masses of individual

Address reprint requests to Professor E. R. Williams, Department of Chemistry, University of California-Berkeley, B42 Hildebrand Hall, Berkeley, CA 94720, USA. E-mail: williams@cchem.berkeley.edu ions up to $100+$ MDa have been measured in FT/ICR MS [4-6] and mass information has been obtained from intact viruses using instruments in which both the $\mathrm{m} / \mathrm{z}$ and the charge of an individual ion are measured directly $[7,8]$.

Although ESI mechanisms [9-16] are still debated, several well-known factors contribute to the extent of charging, including analyte conformation [17, 18], solution $\mathrm{pH}$ [19], instrumental parameters and desolvation conditions [20], solvent and analyte basicity [21-23], and solvent surface tension [13]. While many methods to decrease analyte charging have been developed [21-25], few techniques to increase charging have been reported. Protein ions formed from denaturing solutions can have significantly higher charge states compared with those formed from aqueous solutions where the molecules are in a native or native-like state [17, 18]. Charging of proteins in ESI from denaturing solutions can be further enhanced by adding small amounts of some low-volatility compounds [13, 26, 27]. For example, addition of $m$-NBA to denaturing solutions (methanol/water/acetic acid) containing cytochrome $c$ re- 
sulted in an increase in the maximum charge state from $21+$ to $24+$ and an increase in the average charge state from $17.3+$ to $20.8+$ [27]. This "supercharging" method has been used to produce higher charge state ions for improved structural information from MS/MS experiments [28-32]. The mechanism for supercharging by these added reagents has been controversial. As a charged droplet formed by ESI evaporates, the composition of the droplet will become enriched in the less volatile components [13]. For example, $m$-NBA is significantly less volatile than water or methanol, so the presence of even low initial concentrations of $m$-NBA results in a significant increase in its concentration as droplet evaporation occurs. The surface tension of a solution containing water/methanol/acetic acid with $m$-NBA in which a protein is largely denatured will increase as droplet evaporation occurs and the increased surface tension can lead to enhanced charging of proteins from these solutions [13, 27].

In a recent study of droplet evaporation and discharge dynamics, Grimm and Beauchamp [33] reported that trapped methanol droplets produced by ESI that initially contained $2 \% m$-NBA evaporate down to a core size that remained unchanged for the duration of the analysis $(\sim 1 \mathrm{~s})$, consistent with nearly complete evaporation of the methanol on this long time frame. As the droplet composition changes, several physical properties, including droplet surface tension, effective basicity, and temperature, can change as well. For example, an increased droplet lifetime will result in more collisions as the droplet is introduced into the mass spectrometer, and there will be less evaporative cooling at the later stages when the droplet composition is significantly enhanced with the supercharging reagent. This should result in a droplet with a higher temperature than one that does not contain the supercharging reagent, and this higher temperature may cause destabilization or denaturation of the protein complex [34]. Because of the potential for some additives to affect protein conformation or other factors that can affect charge, either in bulk solution and/or in the electrospray droplet, effects of any individual parameter, such as droplet surface tension, can be more difficult to identify in experiments where many factors contribute to charging.

In the late 1800s, Lord Rayleigh predicted that the maximum number of charges, $z_{\mathrm{R}} e$, which a spherical droplet can hold, is given by eq 1 ;

$$
z_{\mathrm{R}} e=8 \pi\left(\varepsilon_{0} \gamma R^{3}\right)^{1 / 2}
$$

where $z_{\mathrm{R}}$ is the unit charge limit, $e$ is the elementary charge, $\varepsilon_{0}$ is the permittivity of the surrounding medium, $\gamma$ is the surface tension, and $R$ is the droplet radius [35]. The charge on a large ion formed by either a charged residue [36] or ion evaporation [37] process should be related to the overall charge density on a droplet. Because $m$-NBA has a higher surface tension than methanol [27], addition of even small amounts of $m$-NBA to solutions that contain substantial amounts of methanol will result in an increase in the droplet surface tension as methanol preferentially evaporates from the cluster, and enhanced charging of the analyte can occur. For example, addition of $m$-NBA to methanol solutions containing an amine-functionalized dendrimer, poly(propyleneimine (DAB-16)), resulted in a significant increase in charging to this molecule whereas addition of $\mathrm{m}$ NBA to aqueous solutions containing the same dendrimer resulted in a decrease in charging [13]. The surface tension of $m$-NBA ( $50 \pm 5 \mathrm{mN} / \mathrm{m}$ [27]) is higher than that of methanol $\left(22.1 \mathrm{mN} / \mathrm{m}\right.$ at $25^{\circ} \mathrm{C}$ [38]), but lower than that of water $\left(72.0 \mathrm{mN} / \mathrm{m}\right.$ at $25^{\circ} \mathrm{C}$ [38]). Because DAB-16 cannot undergo large conformational changes [39], the studies with this dendrimer provide a more rigorous test of the effects of droplet surface tension on charging than studies using proteins [4044], where competing effects, such as conformational changes, can occur.

Recently, Loo and coworkers found that addition of $m$-NBA and some other compounds, including sulfolane, to aqueous solutions containing noncovalent protein complexes can result in enhanced charging [43, 44]. Based on circular dichroism and H/D exchange measurements, they concluded that addition of $1.0 \% \mathrm{~m}$ NBA to aqueous solutions does not affect the solutionphase structure of myoglobin in the initial solution [43]. Because $m$-NBA has a lower surface tension than water, enrichment of $m$-NBA in an evaporating droplet should result in a lower surface tension and lower charge state in the absence of competing effects, such as protein structural changes. We recently proposed that the enhanced charging observed for protein complexes in ESI from aqueous solutions containing supercharging reagents, such as $m$-NBA, are the result of protein conformational changes that occur as a result of reduced evaporative cooling of the electrospray droplet as the concentration of the low volatility supercharging reagent is increased, resulting in higher droplet temperatures compared with solutions that do not contain these supercharging reagents [34]. The extent of charging and dissociation observed for large macromolecular protein complexes was similar under conditions where solutions were heated in the ESI nanospray emitter, or small amounts of $m$-NBA were added to unheated solutions containing the same noncovalent complex, consistent with thermal denaturation [34]. In contrast to results for large complexes, heated solutions containing smaller proteins, including myoglobin, did not result in a significant change in the observed charge-state distributions whereas addition of $m$-NBA did result in significant increases to the maximum and average charge states. The similar charge-state distribution in heated and unheated solutions without $m$-NBA is consistent with rapid folding of the protein in the unheated part of the tip of the ESI capillary [34] or in the ESI droplet as a result of evaporative cooling.

A powerful method to probe molecular conformation is ion mobility spectrometry, which has been applied to a wide range of interesting problems [45-47]. 
Accurate collision cross sections can be obtained from the arrival times of ions in a drift tube instrument and used to infer information about ion structure. These data can provide a constraint for molecular modeling making it possible to eliminate structures that are calculated to be energetically competitive, but that have different cross sections. Traveling wave ion mobility spectrometry (TWIMS) has been recently developed $[48,49]$ and used to separate conformers of noncovalent complexes [50-54]. In TWIMS, ions are gated into a low-pressure chamber composed of stacked ring electrodes to which a radio frequency of opposite polarity is applied to adjacent rings, resulting in radial confinement of the ions. DC potentials are superimposed on the ring electrodes at a fixed interval in an axialdirected traveling waveform. Ions can "surf" the traveling wave and are separated from other ions of the same charge state based on their collision cross sections.

To determine whether the enhanced charging observed for complexes in aqueous solutions containing supercharging reagents is due to protein conformational changes and unfolding, effects of solution heating and two supercharging reagents, $m$-NBA and sulfolane, on the charging of myoglobin were investigated. TWIMS is used to measure changes to ion conformation that accompany enhanced charging observed with both supercharging reagents. In addition, circular dichroism spectroscopy is used to observe and quantify disruption of secondary structure as a function of sulfolane concentration and solution temperature. Together, these data strongly suggest that higher charge states of myoglobin that are formed with these supercharging reagents added to aqueous solutions are significantly more unfolded than the lower charge state ions, and that this unfolding most likely occurs in the electrospray droplets as a result of chemical and/or thermal denaturation.

\section{Experimental}

Arrival time distributions and mass spectra were acquired using a hybrid quadrupole/ion mobility/timeof-flight instrument (Synapt High Definition Mass Spectrometer; Waters, Milford, MA, USA) equipped with a Z-spray ion source. Ions were formed using nanoelectrospray emitters prepared by pulling borosilicate capillaries (1.0 mm o.d./0.78 mm i.d.; Sutter Instruments, Novato, CA, USA) to a tip i.d. of $\sim 1 \mu \mathrm{m}$ with a Flaming/Brown micropipette puller (model P-87; Sutter Instruments, Novato, CA, USA). A platinum wire (0.127 mm diameter; Sigma, St. Louis, MO, USA) was inserted into the capillary so that contact with the solution was made. Electrospray was initiated and maintained by applying $1-1.3 \mathrm{kV}$ to the wire relative to instrument ground. A cylindrical aluminum collar placed around the capillary, which can be resistively heated with $\mathrm{NiCr}$ wire, was used for experiments at elevated solution temperatures [34]. The temperature of the heating collar was monitored continuously with a thermocouple and temperature meter (Omega, Stamford, CT, USA). Myoglobin solutions were prepared from lyophilized powder (Sigma-Aldrich, St. Louis, MO, USA) by dissolution in $20 \mathrm{mM}$ ammonium acetate, $\mathrm{pH}=7.0$, at a protein concentration of $\sim 20 \mu \mathrm{M}$. $m$-NBA, and sulfolane were purchased from Sigma-Aldrich (St. Louis, MO, USA) and were used without further purification.

The TWIMS mobility cell was operated in linear ramp mode for wave height $(5-16 \mathrm{~V})$ with wave velocity at $300 \mathrm{~m} / \mathrm{s}$, and a pressure of 0.4 Torr of argon. Pressures were maintained at $1.4,1.6 \times 10^{-2}$, and $8.3 \times$ $10^{-7}$ Torr in the backing, trap, and TOF regions, respectively. The TOF analyzer was operated in "V" (single reflectron) mode. Mass spectra were smoothed three times using the Waters MassLynx software Mean smoothing algorithm with a 5 unit window and arrival time distributions were smoothed three times with a 1 unit window.

Circular dichroism (CD) spectra were measured on a Jasco Model 810 spectropolarimeter (JASCO, Inc., Easton, MD, USA). Temperature melts, monitored at 222 $\mathrm{nm}$, were performed with $1 \mu \mathrm{M}$ myoglobin in Milli-Q water (Millipore, Billerica, MA, USA) containing $0 \%$, $2.5 \%, 5.0 \%$, and $7.5 \%$ sulfolane. The solution temperature was increased from 25 to $75^{\circ} \mathrm{C}$ by $1^{\circ} \mathrm{C} / \mathrm{min}$ over $50 \mathrm{~min}$ in a $1 \mathrm{~cm}$ quartz cuvette with constant mixing using a Teflon stir bar. Wavelength scan experiments were performed with the same $\sim 1 \mu \mathrm{M}$ myoglobin in Milli-Q water (Millipore, Billerica, MA, USA) containing $0 \%, 2.5 \%, 5.0 \%$, and $7.5 \%$ sulfolane at fixed temperatures to qualitatively observe protein unfolding.

Equilibrium chemical denaturant melts were obtained by titrating myoglobin solutions $(\sim 10 \mu \mathrm{M}$ in 20 $\mathrm{mM}$ phosphate buffer, $\mathrm{pH} 6.9$ ) containing $0 \%, 2.5 \%$, $5.0 \%$, and $7.5 \%$ sulfolane with $\sim 6 \mathrm{M}$ guanidine hydrochloride (GdmCl) (MP Biomedicals, Solon, OH, USA) in a $1 \mathrm{~cm}$ quartz cuvette with constant mixing using a Teflon stir bar. The $\mathrm{CD}_{222 \mathrm{~nm}}$ unfolding curves were normalized, baseline-corrected, and fit to a two-state model, $\mathrm{U} \rightleftharpoons \mathrm{N}$, where $\mathrm{U}$ is the unfolded state and $\mathrm{N}$ is the native state of myoglobin. The free-energy of folding, $\Delta G_{N}$, was obtained from the fit profiles using eq 2 ,

$$
\mathrm{f}_{\mathrm{u}}=1 /\left(1+\exp \left(\left(-\Delta \mathrm{G}_{\mathrm{N}}-m[\mathrm{GdmCl}]\right) / \mathrm{RT}\right)\right)
$$

where $f_{u}$ is the fraction unfolded, $R$ is the gas constant, $\mathrm{T}$ is temperature, and $m$ is the linear proportionality constant.

Negative ion mass spectra were obtained with a quadrupole time-of-flight mass spectrometer equipped with a Z-spray ion source (Q-TOF Premier, Waters, Milford, MA, USA) [34]. Ions were formed using nanoelectrospray emitters as described above. Myoglobin solutions were prepared from lyophilized powder (SigmaAldrich, St. Louis, MO, USA) by dissolution in $200 \mathrm{mM}$ ammonium acetate, $\mathrm{pH}=8.0$, at a protein concentration of $\sim 10 \mu \mathrm{M}$. 


\section{Results}

\section{Ion Mobility}

$m-N B A$. Nanoelectrospray mass spectra of myoglobin in aqueous $20 \mathrm{mM}$ ammonium acetate solution, $\mathrm{pH} 7.0$, with 0 to $0.40 \% m$-NBA are shown in Figure 1. Without $m$-NBA, the charge-state distribution is narrow and the average and maximum charge states are $7.9+$ and $9+$, respectively (Figure 1a; Table 1). No apomyoglobin or heme is observed, indicating that the transfer of ions from solution through the TWIMS mobility cell and TOF instrument is sufficiently gentle that no dissociation occurs. Addition of $0.03 \% \mathrm{~m}$-NBA (Figure 1b) results in a modest shift in the average charge state to $8.4+$ and no dissociation of the complex occurs. A more significant shift in the average $(9.7+)$ and maximum $(15+)$ charge state is observed with $0.10 \% m$-NBA (Figure 1c). A small abundance of heme ${ }^{+}(m / z 616)$ and the corresponding $10+$ and $9+$ charge states of apomyoglobin are observed. With $0.4 \% \mathrm{~m}$-NBA, the average and maximum charge state is $11.7+$ and $19+$, respectively. $\mathrm{Heme}^{+}$and high charge states of apomyoglobin are also observed with low abundance indicating that a small fraction of the noncovalent complex has dissociated. Results from Loo and coworkers indicate that addition of up to $1.0 \% \mathrm{~m}$-NBA does not affect the conformation of myoglobin in bulk solution [43]. This suggests that the appearance of heme ${ }^{+}$and apomyoglobin at higher concentrations of $m$-NBA is not due to changes in protein conformation as a result of its

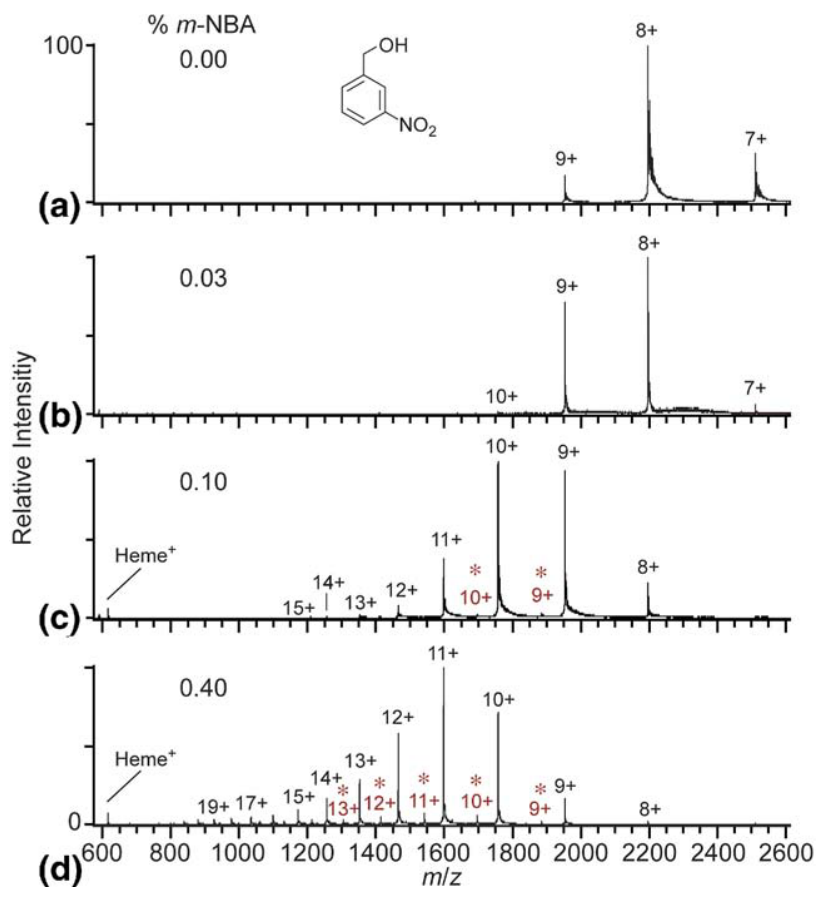

Figure 1. Nanoelectrospray ionization mass spectra of $20 \mu \mathrm{M}$ myoglobin in aqueous ammonium acetate solutions containing (a) $0.00 \%$, (b) $0.03 \%$, (c) $0.10 \%$, and (d) $0.40 \% \mathrm{~m}$-NBA. ${ }^{*}$ Indicates charge states of apomyoglobin. Molecular structure of $m$-NBA is inset in (a).
Table 1. Results for average (and maximum) charge states for holo- and apomyoglobin

\begin{tabular}{lcccc}
\hline & \multicolumn{4}{c}{$\% m$-NBA } \\
\cline { 2 - 5 } & 0.00 & 0.03 & 0.1 & 0.4 \\
\hline \hline Holomyoglobin (+) & $7.9(9)$ & $8.4(10)$ & $9.7(15)$ & $11.7(19)$ \\
Apomyoglobin (+) & $\mathrm{N} / \mathrm{A}$ & $\mathrm{N} / \mathrm{A}$ & $9.5(10)$ & $11.1(13)$ \\
Holomyoglobin (-) & $6.4(7)$ & $6.6(7)$ & $6.6(8)$ & $7.1(8)$ \\
Apomyoglobin (-) & $6.0(6)$ & $5.9(6)$ & $5.9(6)$ & $6.4(7)$ \\
\hline \multicolumn{5}{c}{$\%$ Sulfolane } \\
\cline { 2 - 5 } & 0.0 & 0.1 & 0.4 & 1.0 \\
\hline \hline Holomyoglobin (+) & $7.9(9)$ & $8.3(9)$ & $9.7(16)$ & $11.1(17)$ \\
Apomyoglobin (+) & $\mathrm{N} / \mathrm{A}$ & $\mathrm{N} / \mathrm{A}$ & $\mathrm{N} / \mathrm{A}$ & $12.4(14)$ \\
Holomyoglobin (-) & $6.4(7)$ & $6.7(8)$ & $6.7(8)$ & $6.7(8)$ \\
Apomyoglobin (-) & $6.0(6)$ & $6.0(6)$ & $6.0(6)$ & $6.2(7)$ \\
\hline \multicolumn{5}{c}{ Temperature } \\
\cline { 2 - 5 } & \multicolumn{5}{c}{$30^{\circ} \mathrm{C}$} \\
\hline \hline Holomyoglobin (+) & \multicolumn{5}{c}{ 1:1 Aqueous:acetonitrile } \\
\hline \multicolumn{5}{c}{$8.1(9)$} \\
\cline { 2 - 5 }
\end{tabular}

addition to the initial solution, but rather, dissociation of myoglobin must occur either in the electrospray droplet or in the gas phase.

Ion mobility data for ions formed from each of these solutions were obtained and these data are shown in Figure 2. The relative ion abundances are also given in Figure 2 to show how these change with increasing $m$-NBA concentration. The arrival time distributions (ATDs) of ions with the same charge state that were formed from solutions containing different amounts of $m$-NBA are overlaid. In each case, the ion mobility data for a given charge state do not appear to depend significantly on $m$-NBA concentration. However, these data do show that the higher charge state ions that are formed with $m$-NBA have significantly higher cross sections, consistent with more unfolded structures. The arrival time data were not calibrated, so these data only provide information about relative differences in conformation for each charge state.

There is a single peak in the ATDs of each of the $7+-9+$ charge states, with equal reduced arrival times, calculated by multiplying the estimated peak centroids by the charge state [55], for the $7+$ and $8+(\sim 68 \mathrm{~ms})$ and a slightly longer reduced arrival time for the $9+(\sim 73$ $\mathrm{ms})$, consistent with a single conformer or family of conformers with similar collision cross sections for each charge state. These data, taking into account the nonlinear relationship between arrival time and mobility [56], indicate that the $7+$ and $8+$ ions have similar cross sections and that of the $9+$ is slightly higher. Based on drift tube IMS results for the $8+$ and $9+$ ions of apoand holomyoglobin by Shelimov and Jarrold [57], these 


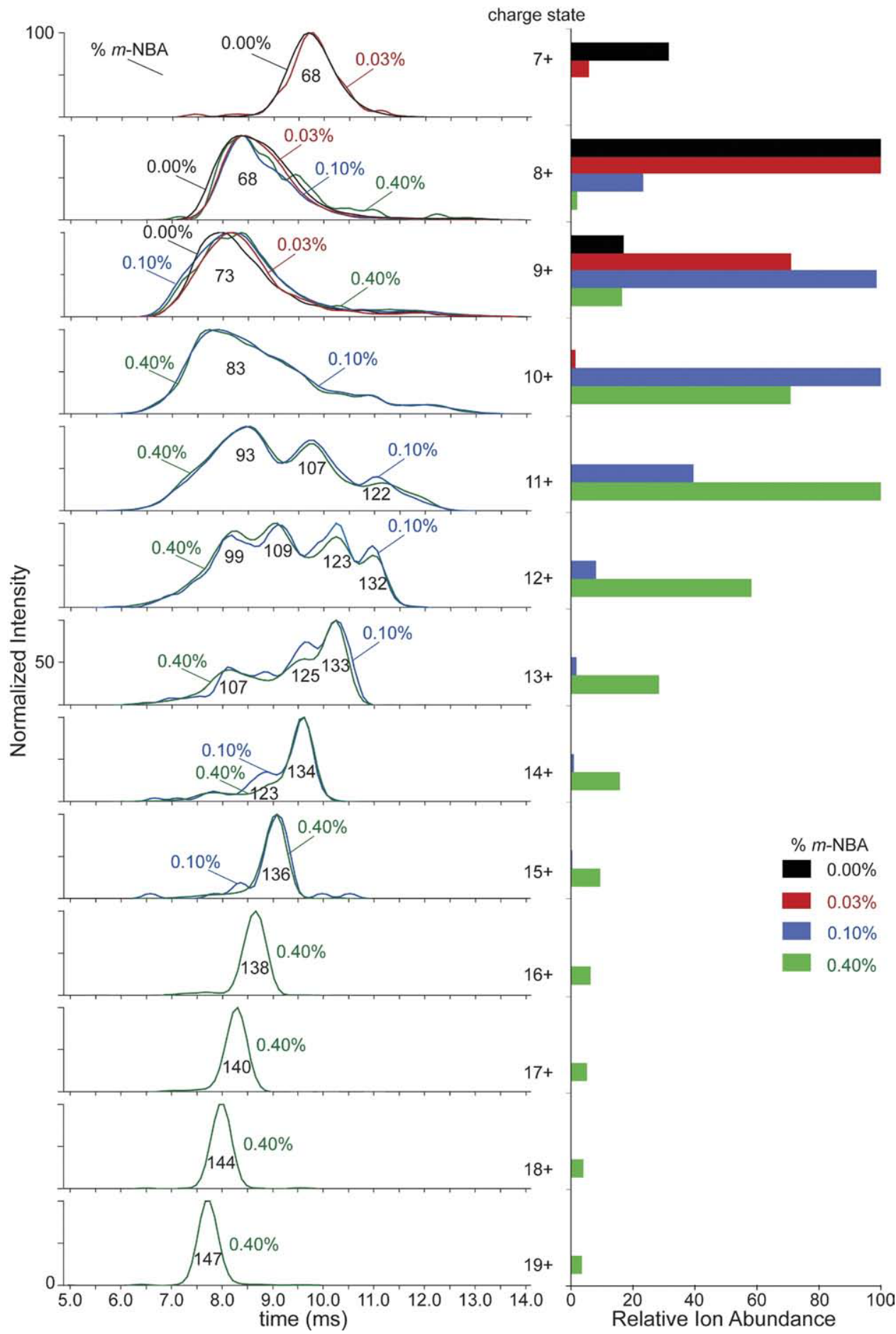

Figure 2. Arrival time distributions (ATD) (left) and relative ion abundances (right) for different charge states of myoglobin formed by nanoelectrospray ionization from aqueous ammonium acetate solutions containing either $0.00 \%, 0.03 \%, 0.10 \%$, or $0.40 \% \mathrm{~m}$-NBA. The ATDs of the same charge state formed from solutions containing different amounts of $m$-NBA are overlaid. The most intense peaks in each ATD are labeled with the reduced arrival time (in ms), calculated by multiplying the estimated peak centroids by the ion charge.

ions likely have relatively compact conformations or families of conformers. Although addition of $m$-NBA dramatically reduces the relative abundances of these low charge state ions, it does not appear to have any measurable effect on their structures. The $10+$ and higher charge states are only formed from solutions containing $m$-NBA. The ATD of the $10+$ is considerably broader with tailing to longer arrival times, and a 
longer reduced arrival time ( $\sim 83 \mathrm{~ms})$ consistent with partial unfolding for some fraction of the population. There are three and four well resolved peaks in the ATDs of the $11+$ and $12+$, respectively, and these peaks occur at longer reduced arrival times than those for the lower charge states, indicating that even the more compact conformers of these charge states are partially unfolded. The 13+ also has multiple peaks in the ATD. The most compact conformer $(\sim 107 \mathrm{~ms})$ is a minor fraction of the population indicating that the majority of these ions are more unfolded. Multiple conformers are also observed for the $14+$ and $15+$ but just a single peak is observed for the $16+-19+$ ATDs. The reduced arrival times for these high charge state ions progressively increase with increasing charge. These data, taking into account the nonlinear relationship between arrival time and mobility [56], indicate a slight increase in cross section with charge, consistent with the trend of increasing collision cross sections measured by Shelimov and Jarrold for denatured apomyoglobin up to $22+$ [57].

Sulfolane. Nanoelectrospray mass spectra of myoglobin (in aqueous $20 \mathrm{mM}$ ammonium acetate, $\mathrm{pH} 7.0$ ) with $0 \%$ to $1.0 \%$ sulfolane are shown in Figure 3. The average and maximum charge states increase with higher concentrations of sulfolane, but the extent of charge enhancement is less than that obtained for a comparable concentration of $m$-NBA. For example, the average and maximum charge states obtained with $0.4 \%$ sulfolane are $9.7+$ and $16+$, respectively, whereas

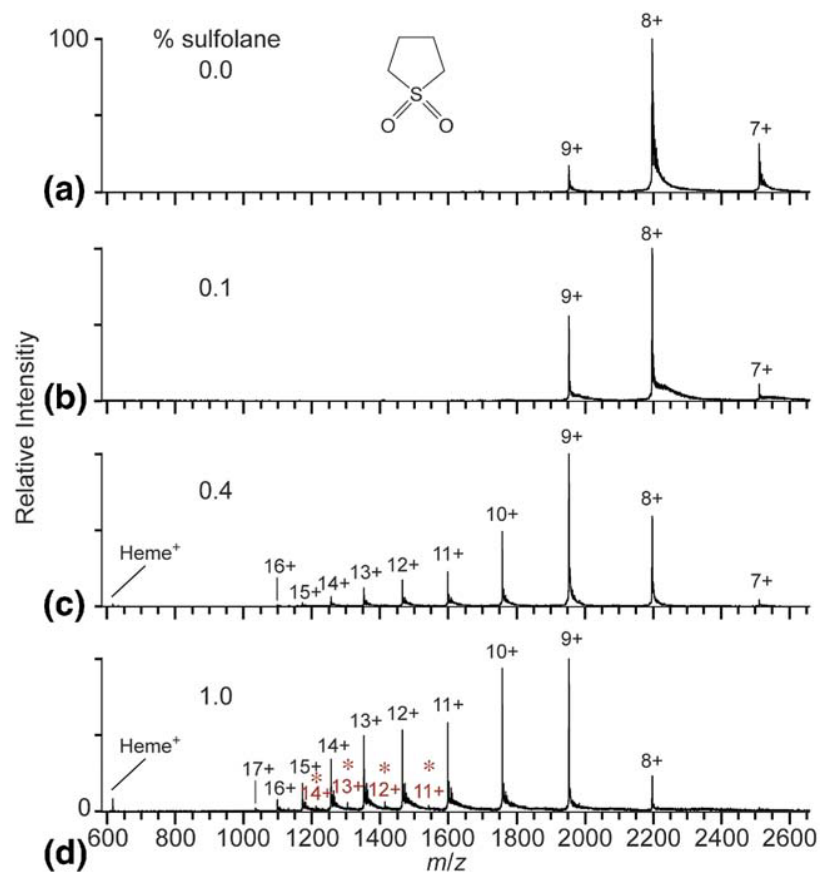

Figure 3. Nanoelectrospray ionization mass spectra of $20 \mu \mathrm{M}$ myoglobin in aqueous ammonium acetate solutions containing (a) $0.0 \%$, (b) $0.1 \%$, (c) $0.4 \%$, and (d) $1.0 \%$ sulfolane. ${ }^{*}$ Indicates charge states of apomyoglobin. Molecular structure of sulfolane is inset in (a). these values for $0.4 \% m-\mathrm{NBA}$ are $11.7+$ and $19+$. The results obtained for sulfolane are similar to those reported by Loo and coworkers, who observed a maximum charge state of $18+$ with a $276 \mathrm{mM}$ sulfolane solution $(\sim 2.6 \%$, vol/vol). In contrast, they report less supercharging with $m$-NBA than what is obtained under the conditions of these experiments (Figure 1).

The ATDs and reduced arrival times for ions formed from solutions containing sulfolane are shown in Figure 4 , and these data are overlaid the same as those in Figure 2. As was the case with $m$-NBA, the ATD data for a given charge state does not depend significantly on the sulfolane concentration for most charge states, but the high charge states that are only formed with sulfolane present are significantly unfolded. The ATDs for each charge state (Figure 4) are very similar to the corresponding data obtained with $m$-NBA (Figure 2), suggesting comparable extents of unfolded structure. There are some differences in relative peak intensities within a distribution, e.g., data for 13+ in Figures 2 and 4 , but the reduced arrival times of these peaks are nearly identical, indicating that the same conformers or multiple unresolved conformer families exist, but the relative populations of these conformers can differ slightly.

\section{Solution Heating}

Nanoelectrospray mass spectra of myoglobin in aqueous $20 \mathrm{mM}$ ammonium acetate, $\mathrm{pH} 7.0$, with the solution in the nanospray capillary heated to 30 and $88^{\circ} \mathrm{C}$ are shown in Figure 5. There is no increase in the maximum charge state and only a minor increase in the average charge state at the higher temperature. This result is consistent with previous results [34], although no loss of heme is observed under these conditions. The ATDs of the $7+-9+$ ions do not depend on the capillary temperature and the data for these charge states are very similar to those for the corresponding charge states formed from unheated solutions that contain either $m$-NBA or sulfolane.

\section{Circular Dichroism Spectroscopy}

The stability of the native state of myoglobin as a function of sulfolane concentration was investigated using circular dichroism at $222 \mathrm{~nm}$, which reflects the extent of $\alpha$ helical structure in proteins [58]. In these experiments, solutions containing $\sim 10 \mu \mathrm{M}$ myoglobin in $20 \mathrm{mM}$ phosphate buffer, $\mathrm{pH}=6.9$, and either $0 \%$, $2.5 \%, 5.0 \%$, or $7.5 \%$ sulfolane were titrated with $\sim 6 \mathrm{M}$ guanidine hydrochloride. Unfolding curves are shown in Figure 6a. Higher concentrations of sulfolane could not be used because sulfolane absorbs at these wavelengths and therefore interferes with the measurement near $10 \%$ concentration. Also, $m$-NBA was not used due to interference with the measurement at concentrations $\geq 0.1 \%$. The $\mathrm{CD}_{222 \mathrm{~nm}}$ denaturation profiles were normalized, baseline-corrected, and fit to a two-state 


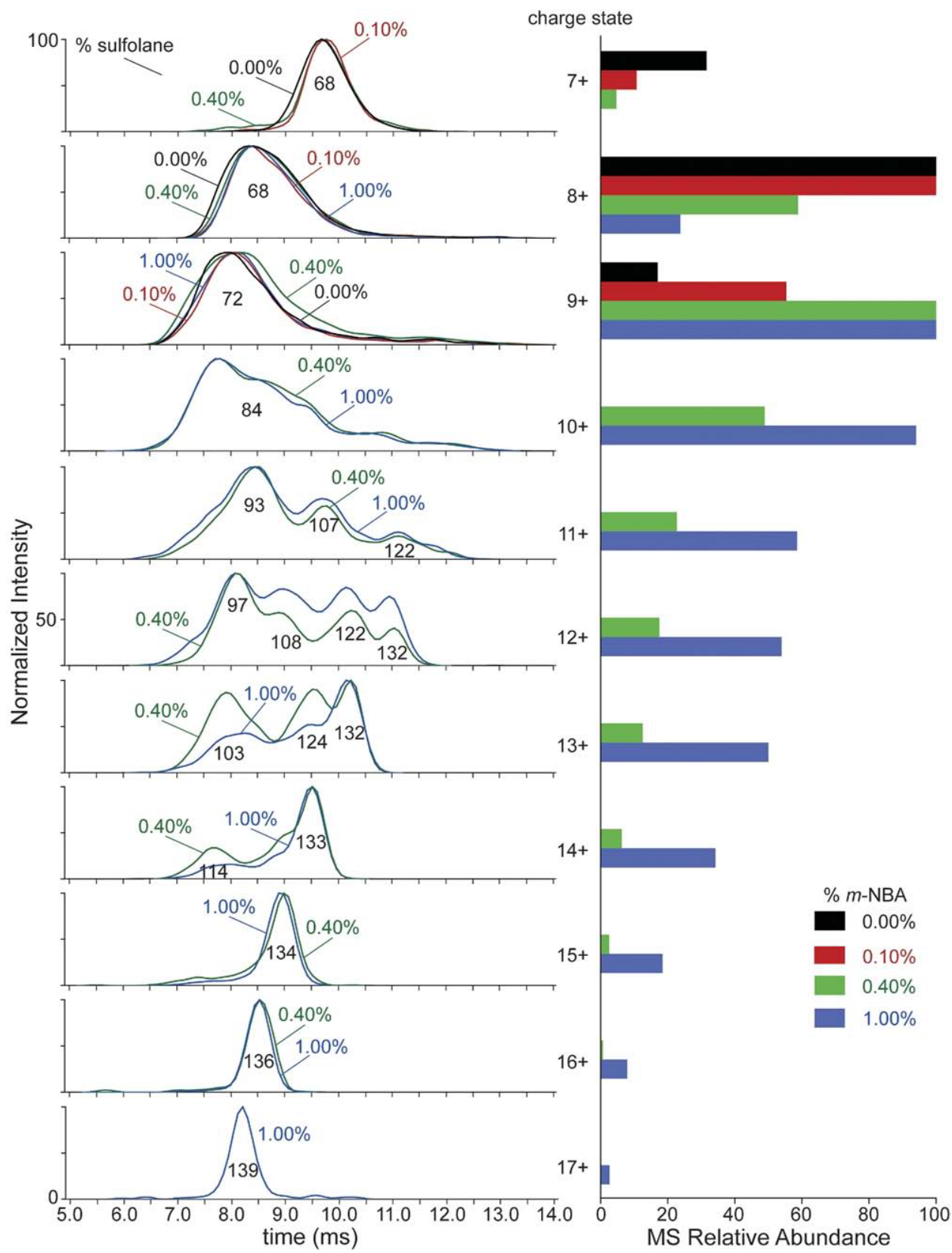

Figure 4. Arrival time distributions (ATD) (left) and relative ion abundances (right) for different charge states of myoglobin formed by nanoelectrospray ionization from aqueous ammonium acetate solutions containing either $0.0 \%, 0.1 \%, 0.4 \%$, or $1.0 \%$ sulfolane. The ATDs of the same charge state formed from solutions containing different amounts of sulfolane are overlaid. The most intense peaks in each ATD are labeled with the reduced arrival time (in ms), calculated by multiplying the estimated peak centroids by the ion charge.

model, from which the free energies for folding are obtained using eq 2 (average $m=5.1 \pm 0.3 \mathrm{kcal} / \mathrm{mol} /$ $\mathrm{M})$. The free energies of folding as a function of sulfolane concentration are shown in Figure 6a. These free energies are linear $\left(R^{2}=0.99\right)$ with respect to sulfolane concentration and have a slope of $1.5 \pm 0.1 \mathrm{kcal} / \mathrm{mol} / \mathrm{M}$. Thus, sulfolane significantly destabilizes the native structure of myoglobin with increasing concentration.

No observable loss of helicity occurs with even the highest sulfolane concentration that was used for $\mathrm{CD}_{222 \mathrm{~nm}}$ analysis $(7.5 \%)$ at room-temperature. Therefore, the relative helical content of myoglobin was measured as a function of temperature between 25 and $75{ }^{\circ} \mathrm{C}$ for solutions containing $0 \%, 2.5 \%, 5.0 \%$, and $7.5 \%$ sulfolane (Figure $6 \mathrm{~b}$ ). Without sulfolane, myoglobin retains considerable helicity at higher temperatures (Figure 6b), consistent with previous $\mathrm{CD}_{222 \mathrm{~nm}}$ measurements [59]. The effects of sulfolane at higher concentration and higher temperature are more pronounced. A significant loss of helicity occurs between 50 and $65^{\circ} \mathrm{C}$ at the highest concentra- 

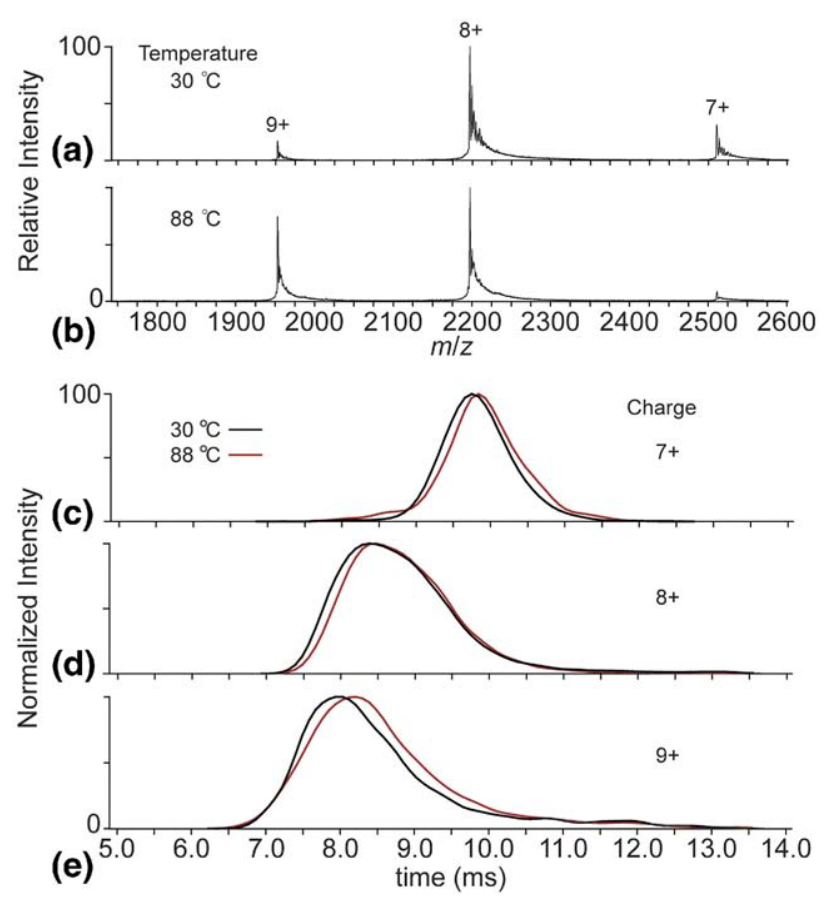

Figure 5. Nanoelectrospray ionization mass spectra (a) and (b) and arrival time distributions (c) $-(\mathbf{e})$ of the $7+-9+$ charge states of myoglobin formed from aqueous ammonium acetate solutions at 30 and $88^{\circ} \mathrm{C}$.

tion. Effects at even higher temperature were not investigated because myoglobin can aggregate at temperatures above this range [60]. CD spectra of $\sim 10 \mu \mathrm{M}$ myoglobin with $5 \%$ sulfolane at $25,35,45,55,65$, and $75^{\circ} \mathrm{C}$ are inset in Figure $6 \mathrm{~b}$. These spectra clearly show that significant unfolding of myoglobin occurs by $75^{\circ} \mathrm{C}$.

\section{Supercharging of Negative Ions}

Negative ion nanoelectrospray mass spectra of $10 \mu \mathrm{M}$ myoglobin (in aqueous $200 \mathrm{mM}$ ammonium acetate, $\mathrm{pH}$ 8.0 ) with $0 \%$ to $0.4 \% \mathrm{~m}$-NBA and $0 \%$ to $1.0 \%$ sulfolane are shown in Figure 7. Charging is enhanced with increasing concentrations of both reagents, with $m$-NBA having a greater effect than sulfolane on a per mole basis (Table 1). Some heme ${ }^{-}$and apomyoglobin with slightly higher average charge is observed with $0.4 \%$ $m$-NBA (Table 1). The extent of supercharging is significantly less than that observed for positive ions formed from the same solutions (Table 1).

Konermann and Douglas previously reported that the extent of charging of denatured ubiquitin and cytochrome $c$ is much lower for negative ions than for positive ions [61]. To determine if the extent of charging of myoglobin for negative ions has a similar insensitivity to protein conformation, positive and negative ion mass spectra of a $5 \mu \mathrm{M}$ myoglobin solution containing $50 \%$ acetonitrile were obtained with all instrument parameters the same except for the instrument polarity (Figure 8). Significant loss of native structure of myoglobin in this solution was confirmed by CD spectros- copy, and is consistent with apomyoglobin as the major charge state distribution in both mass spectra. The extent of charging for positive ions is much greater than for negative ions (Figure 8, Table 1). These results suggest that the extent of charging of myoglobin for negative ions can be similarly insensitive to structural change as was reported for denatured ubiquitin and cytochrome $c$ [61]. This relative insensitivity to structure could account for the much lower supercharging observed for negative ions compared with positive ions if
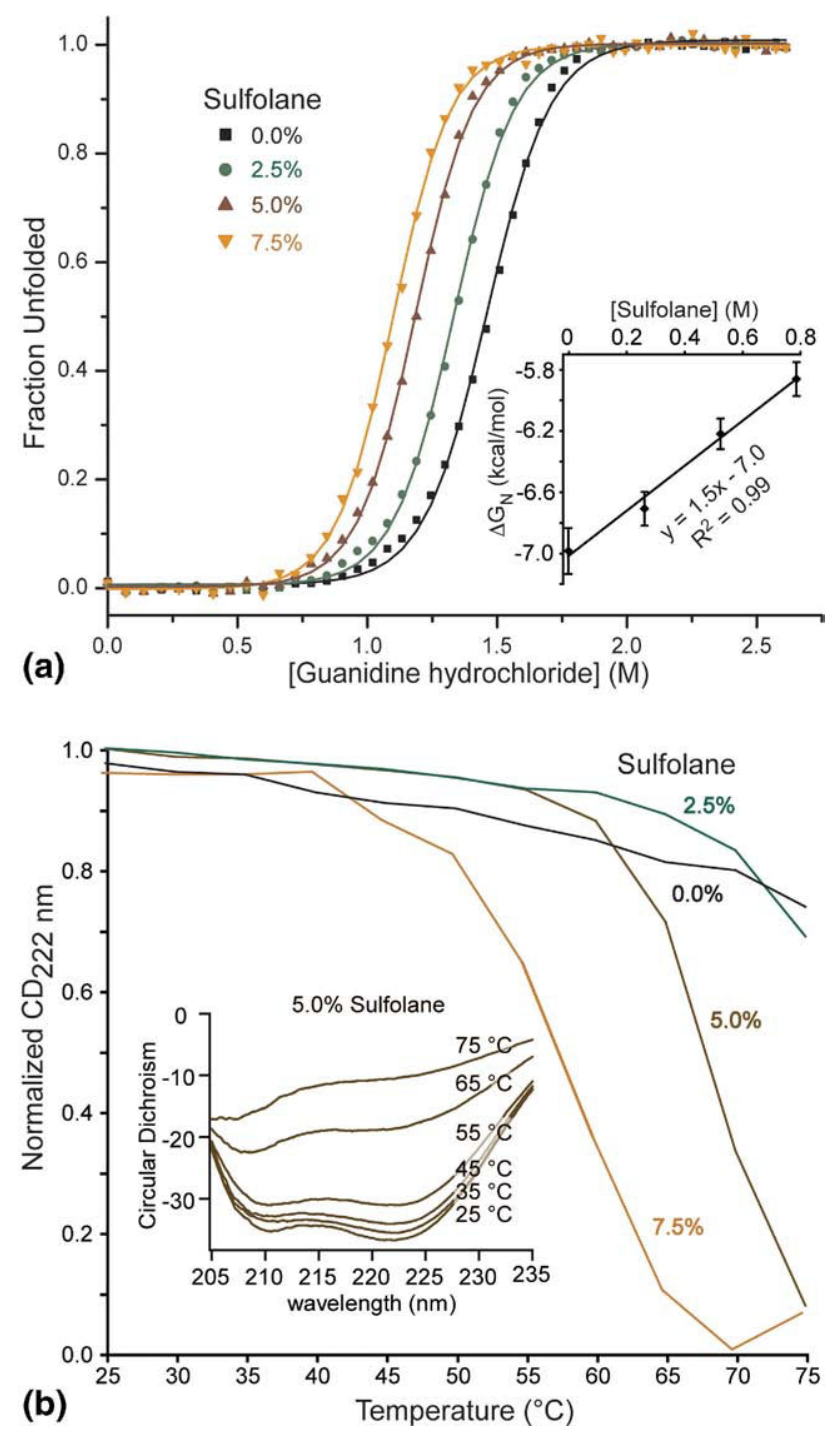

Figure 6. Circular dichroism (222 nm) denaturation profiles of 10 $\mu \mathrm{M}$ myoglobin in solutions containing $0 \%, 2.5 \%, 5.0 \%$, or $7.5 \%$ sulfolane. (a) Guanidine hydrochloride denaturation profiles; free energies for folding, $\Delta G_{N}$, were obtained from fit profiles using eq 2 , with average $m=5.1 \pm 0.3 \mathrm{kcal} / \mathrm{mol} / \mathrm{M}$. Inset: $\Delta \mathrm{G}_{\mathrm{N}}$ values obtained for each concentration of sulfolane fit to a linear function with a slope of $1.5 \mathrm{kcal} / \mathrm{mol} / \mathrm{M}$ of sulfolane and an intercept of $-7.0 \mathrm{kcal} / \mathrm{mol}\left(\mathrm{R}^{2}=0.99\right)$. (b) Temperature denaturation profiles showing effects of sulfolane concentration on the relative helical content of myoglobin; CD spectra of myoglobin with $5 \%$ sulfolane as a function of temperature inset. 


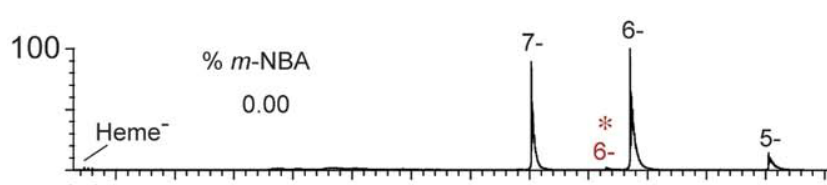

(a)

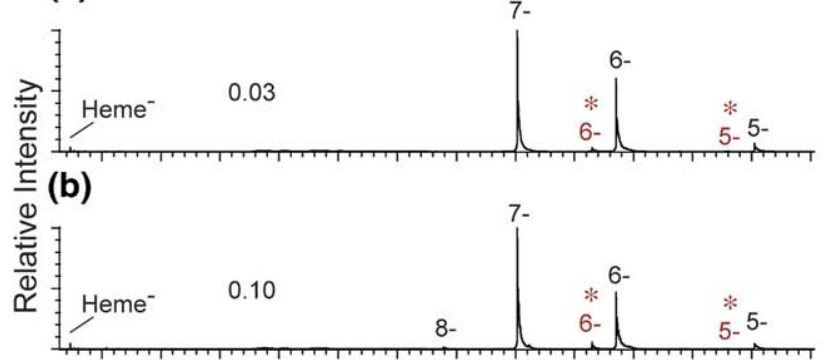

(c)

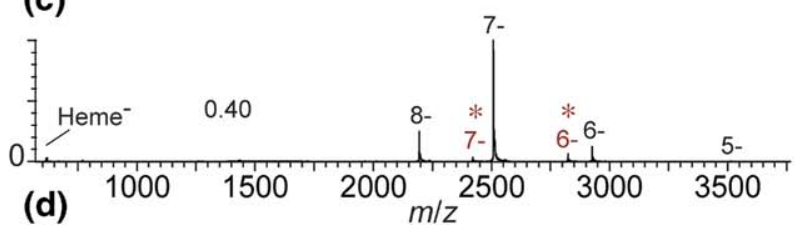

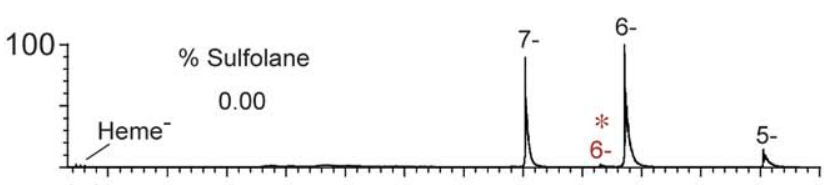

(e)
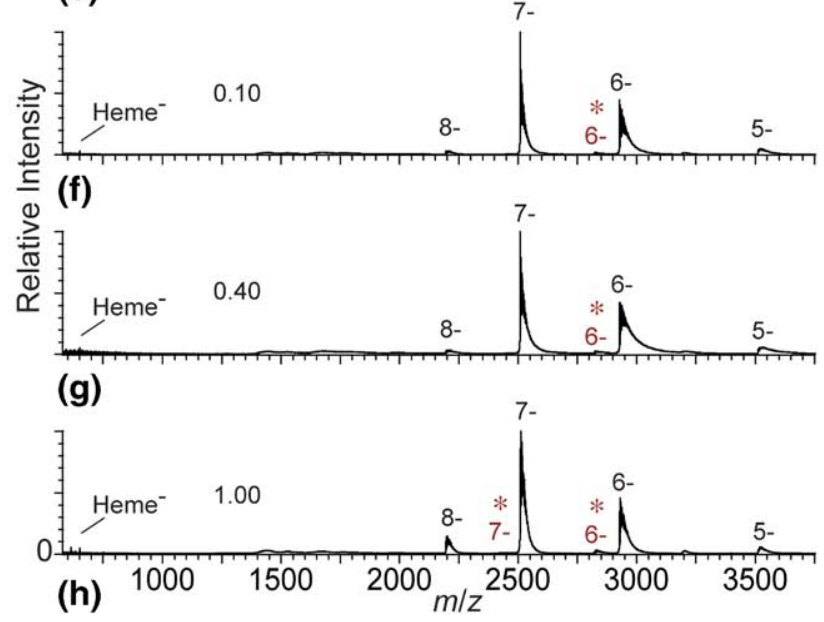

Figure 7. Negative ion nanoelectrospray ionization mass spectra of $10 \mu \mathrm{M}$ myoglobin in $200 \mathrm{mM}$ ammonium acetate, $\mathrm{pH}=8.0$, solution containing (a) $0 \%$, (b) $0.03 \%$, (c) $0.10 \%$, or (d) $0.40 \% \mathrm{~m}-\mathrm{NBA}$, or (e) $0 \%$, (f) $0.10 \%$, (g) $0.40 \%$, or (h) $1.0 \%$ sulfolane.

supercharging in purely aqueous solutions is caused by a change in protein structure as a result of chemical and/or thermal denaturation in the electrospray droplet. In contrast to these results, Fenselau and coworkers observed much higher charge states for negative myoglobin ions electrosprayed from 50\% methanol solutions at both acidic and basic $\mathrm{pH}$ [62]. This discrepancy illustrates the difficulty of trying to ascribe ESI analyte charging phenomena, including supercharging, to a single parameter, where many competing factors, including instrumental parameters, are at work.

\section{Discussion}

The ion mobility data provide compelling evidence that the higher charge state ions of myoglobin, formed when small amounts of either $m$-NBA or sulfolane are added to aqueous solutions, are significantly more unfolded than the lower charge state ions formed with or without the supercharging reagents. The charge-state distributions in ESI mass spectra can reflect the conformation of proteins in solution [17, 18], with folded native-like structures having fewer charges than structures that are

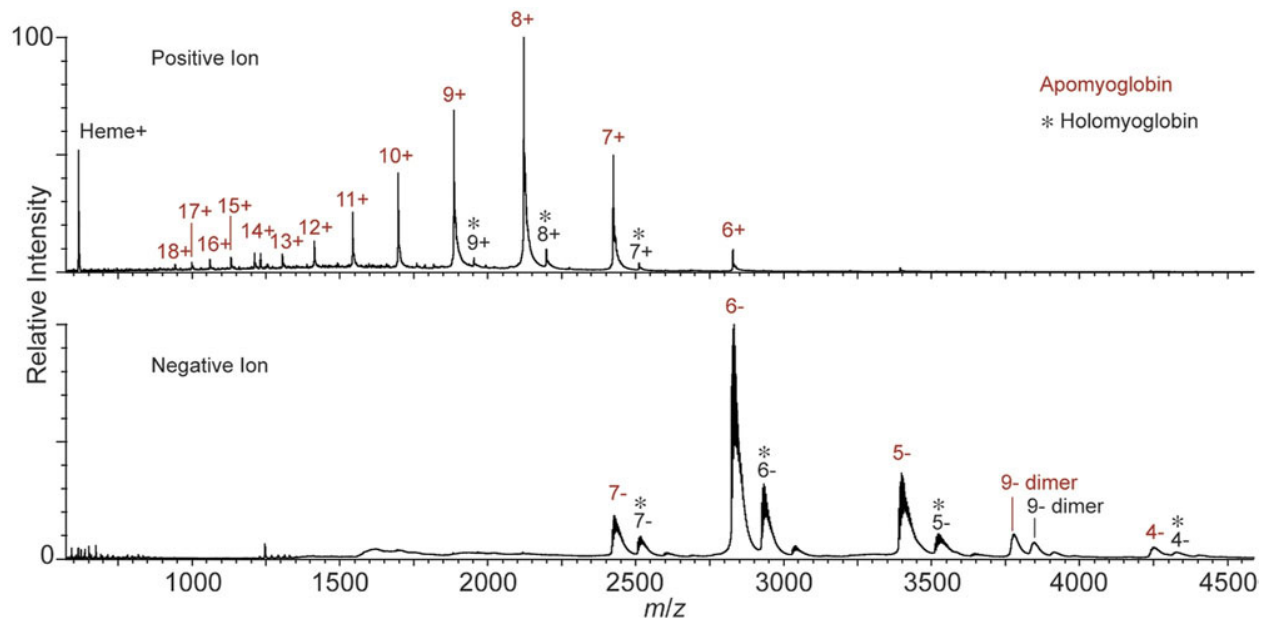

Figure 8. Positive (top) and negative (bottom) nanoelectrospray ionization mass spectra for $10 \mu \mathrm{M}$ myoglobin in a 1:1 $200 \mathrm{mM}$ ammonium acetate ( $\mathrm{pH}$ 7.0): acetonitrile solution. Both CD spectra and the high abundances of apomyoglobin indicate substantial disruption of the native protein structure from these solutions. 
more unfolded. The increased charging observed with higher concentrations of supercharging reagents is consistent with a change in the solution-phase conformation from more native to more unfolded structures. Both our CD results and those of Loo and coworkers $[43,44]$ indicate that neither $m$-NBA nor sulfolane significantly affect the secondary structure of myoglobin when these reagents are in the initial solutions at low concentration. In addition, results from hydrogen deuterium exchange (H/DX) experiments with both ubiquitin and the protein heterodimer barnase-barstar, indicate that tertiary and quaternary structure is also not significantly affected by the low concentrations of supercharging reagent in the initial solution [63].

Our CD results clearly demonstrate that myoglobin is destabilized with increasing sulfolane concentration by $1.5 \pm 0.1 \mathrm{kcal} / \mathrm{mol} / \mathrm{M}$. By comparison, the guanidine hydrochloride used in these experiments destabilizes myoglobin by $\sim 4.7 \mathrm{kcal} / \mathrm{mol} / \mathrm{M}$. Therefore, sulfolane is $\sim 30 \%$ as effective as guanidine hydrochloride, a widely used chemical denaturant, for destabilizing the native structure of myoglobin. Thus, the conformational change of myoglobin caused by these supercharging reagents, as indicated both by the increasing chargestate distribution and by the TWIMS data, must occur in solution during droplet evaporation or in the final stages of ion desolvation. Unfolding after formation of the "naked" ions would not by itself result in enhanced charging.

Denaturation of myoglobin in the electrospray droplet could occur either by chemical or thermal denaturation, or a combination of both. Droplet evaporation results in increased concentrations of these supercharging reagents owing to their low vapor pressures. As clearly shown by our $\mathrm{CD}$ experiments, the native structure of myoglobin is progressively destabilized with increasing sulfolane concentration, resulting in a greater fraction of these ions that are denatured in the electrospray droplet. In addition, the droplet temperature will increase owing to less evaporative cooling at the later stages of the droplet lifetime.

The similar ion mobility data for the low charge state ions formed with either $m$-NBA or sulfolane compared with when these supercharging reagents are not present indicate that gross structural changes during ESI do not occur to the entire solution-phase population when low initial concentrations of these supercharging reagents are used. Because the composition of droplets that undergo Rayleigh fission may not be uniform, the lower charge state ions may be formed from those droplets that contain less reagent. There could also be structural differences not reflected in the ion mobility data. However, it is difficult to draw definitive conclusions from these data because many different factors, in addition to structure, affect charging, and additional structural changes may also take place in the gas phase.

\section{Conformational Changes in the Electrospray Droplet}

Significant changes in the secondary and tertiary structure of sperm whale myoglobin occur rapidly at temperatures $>\sim 70{ }^{\circ} \mathrm{C}[60]$, with at least some loss of heme expected [64]. The similar appearance of the nanospray mass spectra at 30 and $88^{\circ} \mathrm{C}$ (Figure 5) is consistent with refolding occurring at lower temperature. The ion mobility data in Figure 5 clearly demonstrate that the gas-phase ions formed from the higher temperature solutions have folded conformations with similar cross sections to those ions formed from unheated solutions, consistent with solution-phase folding in the tip of the nano-ESI capillary or potentially in the ESI droplet. Results from previous circular dichroism experiments indicate that myoglobin can fold in the ms time frame $[65,66]$, which is sufficiently fast for refolding to occur in the droplet, which is evaporatively cooled, and it has been shown that myoglobin can recover a substantial fraction of its helicity after thermal denaturation [66]. In addition, the temperature-dependent CD measurements made with $0 \%$ sulfolane described above show that at $75{ }^{\circ} \mathrm{C}$, there is little loss of helical content, so even modest evaporative cooling could allow the protein to refold to a more native state. Therefore, as evidenced by the fast folding observed in these capillary heating experiments, and the ms timescale for folding $[65,66]$ and unfolding [67-69] measured by others, it is reasonable to postulate that an unfolding transition can also occur on the timescale of ESI.

The $\mathrm{CD}_{222 \mathrm{~nm}}$ guanidinium denaturation profiles obtained here show that chemical denaturation is also likely as the concentration of the supercharging reagent in the droplet increases. For example, with the $25^{\circ} \mathrm{C}$ denaturing strength measured in these experiments $(1.5 \pm 0.1 \mathrm{kcal} / \mathrm{mol} / \mathrm{M})$, a solution initially containing $1 \%$ sulfolane $(0.11 \mathrm{M})$ would only need to become enriched in sulfolane by $\sim 40 \times$ to destabilize the native state of myoglobin $\sim 7 \mathrm{kcal} / \mathrm{mol}$ so that the free energies of the native and unfolded states are equal. Because sulfolane is significantly less volatile than water (sulfolane b.p. $=287.6^{\circ} \mathrm{C}$ at 760 Torr), this or even greater extents of enrichment is plausible. Furthermore, results from the temperature-dependent $\mathrm{CD}_{222} \mathrm{~nm}$ measurements show that the effects of sulfolane become more pronounced with increasing temperature. Higher droplet temperatures will reduce the magnitude of enrichment necessary to reach a $\Delta \mathrm{G}_{\mathrm{N}} \approx 0 \mathrm{kcal} / \mathrm{mol}$ for myoglobin. Evidence for enrichment of the supercharging reagent can be inferred from the results of Loo and coworkers who observed supercharging reagents adducted to their protein analytes in the gas phase [43].

Under the conditions of these experiments, the extent of supercharging obtained with sulfolane is less than that obtained with $m$-NBA on a per mole basis, although in high enough concentration, sulfolane can supercharge to similar levels observed with lower concentrations of $m$-NBA. The difference in supercharging 
extents may be attributed in part to the different boiling points of these two compounds. Sulfolane has a lower estimated boiling point than $m$-NBA $\left(101^{\circ} \mathrm{C}\right.$ versus $177^{\circ} \mathrm{C}$ at 3 Torr, respectively; value for sulfolane at $287^{\circ} \mathrm{C}$ and 760 Torr [38] is adjusted to 3 Torr [70]). This would result in a lower extent of droplet heating for solutions containing sulfolane as compared with solutions with $m$-NBA at the same initial concentration. Again, it is difficult to draw definitive conclusions about the influence of just a single physical parameter because many competing factors contribute to the extent of charging observed in ESI mass spectra, including analyte conformation $[17,18]$, surface tension $[13,26$, 27], droplet size [71], instrumental parameters [20], solvent and analyte gas-phase basicity [21-23, 43], etc.

Loo and coworkers have recently suggested that a significant factor in protein complex supercharging from aqueous solution is proton transfer as a result of the relatively low solution- and gas-phase basicity of the supercharging reagents compared with the protein complex analyte [43]. In addition, they suggest that the supercharged protein complexes may be transferred to the gas phase with the native or native-like conformation intact [43], although the broader charge state distributions they observed are more consistent with some structural changes to the native conformation(s). $m$ NBA supercharges to a greater extent than sulfolane on a per mole basis for both positive and negative ions (Figure 7, Table 1) suggesting that proton transfer is not the primary origin of charge enhancement.

As clearly shown in a number of previous studies, solvent and analyte gas-phase basicity does affect charging in electrospray ionization [21-23, 43], so it cannot be ignored in a study of the mechanism of supercharging. However, our results strongly suggest that protein unfolding is the primary cause of supercharging from aqueous solutions. Loo and coworkers have called into question the charged residue mechanism and the role of solvent surface tension in the ionization of protein complexes because their calculations indicate that these supercharged ions exceed the charge limit predicted by the model for a protein electrosprayed from aqueous solutions containing $m$ NBA, sulfolane, and benzyl alcohol (another reagent found to supercharge) [43]. However, those chargelimit calculations were made assuming a compact spherical shape of the protein and a spherical droplet, whereas the results shown here strongly suggest that unfolding occurs in the electrospray droplet when proteins are supercharged from purely aqueous solution.

\section{Conclusions}

Addition of either $m$-NBA or sulfolane to aqueous solutions can increase both the average and maximum charge state of proteins and protein complexes. Because both $m$-NBA and sulfolane have higher boiling points than water, the concentration of these supercharging reagents will increase as droplet evaporation occurs, which will lower the droplet surface tension, and hence lower the maximum charge density of the droplet. As the concentration of the low vapor pressure supercharging reagent increases, evaporative cooling will be reduced compared with droplets that do not contain these supercharging reagents. With reduced evaporative cooling to offset collisional heating that occurs in the ESI interface, the temperature of the droplet will be higher late in the droplet lifetime after most of the more volatile solvent has evaporated. Results from TWIMS experiments clearly show that the higher charge state ions formed from solutions containing these supercharging reagents have conformations that are significantly more unfolded than those of lower charge state ions originating from solutions either with or without the supercharging reagents. Results from CD experiments clearly demonstrate a direct relationship between myoglobin destabilization and sulfolane concentration. Because $m$-NBA and sulfolane do not appear to affect protein conformation at the low concentrations in the initial solutions, these results strongly suggest that protein unfolding occurs in the electrospray droplet as a result of chemical and/or thermal denaturation owing to higher concentrations of the supercharging reagent and elevated droplet temperature. Thus, the effects of protein unfolding on charging are greater than those of decreased droplet surface tension in these experiments, although other factors, such as basicity of the supercharging reagents, almost certainly influence the extent of charging as well. In contrast, for analytes that undergo only minimal conformational changes, such as many denatured proteins in water/methanol/acetic acid solutions or DAB-16 [13], droplet surface tension appears to play a primary role in the mechanism of supercharging.

Because droplet evaporation occurs rapidly, addition of these supercharging reagents to solutions containing functional proteins or protein complexes in aqueous solutions can result in denaturation and unfolding after the electrospray droplet is formed. This capability may find applications in protein folding studies where inducing conformational changes is desired. This protein denaturing method could also be used to unfold proteins in solution-phase $H / D$ exchange experiments to produce supercharged ions that are more readily dissociated using electron capture or electron-transfer dissociation. There is increasing evidence that the extent of $\mathrm{H} / \mathrm{D}$ scrambling can be minimal with electron capture [72-75] and electron-transfer dissociation [76-78] so that information about the rates of exchange in solution can be obtained from gas-phase dissociation experiments with individual amino acid resolution. Initial results in our laboratory with solution $\mathrm{H} / \mathrm{D}$ exchange of ubiquitin followed by top-down electron-transfer dissociation indicate that addition of small amounts of $m$-NBA to the solutions does not affect H/D exchange rates compared with rates measured by NMR under comparable conditions [63]. Addition of $m$-NBA in these experiments has the advantage that $\mathrm{H} / \mathrm{D}$ exchange data can be continuously acquired at room 
temperature without the need to quench the exchange reaction, and highly charged ions, which are ideal for either electron-transfer or electron capture dissociation, are formed, which may make it possible to extend top-down $\mathrm{H} / \mathrm{D}$ exchange experiments to even larger proteins and protein complexes.

\section{Acknowledgments}

The authors thank Don Harris and the Waters Corporation for generously making available a Synapt High Definition Mass Spectrometer demonstration instrument for these studies, and thank the National Institutes of Health (E.R.W.: R01-GM064712 and B.A.K.: R01-AI077703) for financial support.

\section{References}

1. Han, X. M.; Jin, M.; Breuker, K.; McLafferty, F. W. Extending Top-Down Mass Spectrometry to Proteins with Masses Greater Than 200 Kilodaltons. Science 2006, 314, 109-112.

2. Marshall, A. G.; Hendrickson, C. L.; Jackson, G. S. Fourier Transform Ion Cyclotron Resonance Mass Spectrometry: A Primer. Mass Spectrom. Rev. 1998, 17, 1-35.

3. Perry, R. H.; Cooks, R. G.; Noll, R. J. Orbitrap Mass Spectrometry: Instrumentation, Ion Motion and Applications. Mass Spectrom. Rev. 2008, 27, 661-699.

4. Smith, R. D.; Cheng, X.; Bruce, J. E.; Hofstadler, S. A.; Anderson, G. A Trapping, Detection and Reaction of Very Large Single Molecular-Ions by Mass-Spectrometry. Nature 1994, 369, 137-139.

5. Bruce, J. E.; Cheng, X.; Bakhtiar, R.; Wu, Q.; Hofstadler, S. A.; Anderson, G. A.; Smith, R. D. Trapping, Detection, and Mass Measurement of Individual Ions in a Fourier-Transform Ion-Cyclotron Resonance MassSpectrometer. I. Am. Chem. Soc. 1994, 116, 7839-7847.

6. Chen, R. D.; Cheng, X. H.; Mitchell, D. W.; Hofstadler, S. A.; Wu, Q. Y.; Rockwood, A. L.; Sherman, M. G.; Smith, R. D. Trapping, Detection, and Mass Determination of Coliphage T4 DNA Ions of 10(8) Da by ElectrosprayIonization Fourier-Transform Ion-Cyclotron Resonance Mass-Spectrometry. Anal. Chem. 1995, 67, 1159-1163.

7. Fuerstenau, S. D.; Benner, W. H.; Thomas, J. J.; Brugidou, C.; Bothner, B.; Siuzdak, G. Mass Spectrometry of an Intact Virus. Angew. Chem. Int. Ed. 2001, 40, 542-544.

8. Chang, H. C. Ultrahigh-Mass Mass Spectrometry of Single Biomolecules and Bioparticles. Ann. Rev. Anal. Chem. 2009, 2, 169-185.

9. Fenn, J. B. Ion Formation from Charged Droplets - Roles of Geometry, Energy, and Time. J. Am. Soc. Mass Spectrom. 1993, 4, 524-535.

10. de la Mora, J. F. Electrospray Ionization of Large Multiply Charged Species Proceeds Via Dole's Charged Residue Mechanism. Anal. Chim. Acta 2000, 406, 93-104.

11. Cech, N. B.; Enke, C. G. Practical Implications of Some Recent Studies in Electrospray Ionization Fundamentals. Mass Spectrom. Rev. 2001, 20, 362-387.

12. Cech, N. B.; Enke, C. G. Effect of Affinity for Droplet Surfaces on the Fraction of Analyte Molecules Charged During Electrospray Droplet Fission. Anal. Chem. 2001, 73, 4632-4639.

13. Iavarone, A. T.; Williams, E. R. Mechanism of Charging and Supercharging Molecules in Electrospray Ionization. J. Am. Chem. Soc. 2003, 125, 2319-2327.

14. Hogan, C. J.; Carroll, J. A.; Rohrs, H. W.; Biswas, P.; Gross, M. L. Charge Carrier Field Emission Determines the Number of Charges on Native State Proteins in Electrospray Ionization. J. Am. Chem. Soc. 2008, 130, 6926-6927.

15. Kebarle, P.; Verkerk, U. H. Electrospray: From Ions in Solution to Ions in the Gas Phase, What We Know Now. Mass Spectrom. Rev. 2009, 28, $898-917$.

16. Grandori, R. Origin of the Conformation Dependence of Protein Charge-State Distributions in Electrospray Ionization Mass Spectrometry. J. Mass Spectrom. 2003, 38, 11-15.

17. Chowdhury, S. K.; Katta, V.; Chait, B. T. Probing Conformational Changes in Proteins by Mass Spectrometry. J. Am. Chem. Soc. 1990, 112, 9012-9013.

18. Konermann, L.; Douglas, D. J. Equilibrium Unfolding of Proteins Monitored by Electrospray Ionization Mass Spectrometry: Distinguishing Two-State from Multi-State Transitions. Rapid Commun. Mass Spectrom. 1998, 12, 435-442.

19. Wang, G. D.; Cole, R. B. Disparity Between Solution-Phase Equilibria and Charge-State Distributions in Positive-Ion Electrospray Mass Spectrometry. Org. Mass Spectrom. 1994, 29, 419-427.

20. Page, J. S.; Kelly, R. T.; Tang, K.; Smith, R. D. Ionization and Transmission Efficiency in an Electrospray Ionization-Mass Spectrometry Interface. J. Am. Soc. Mass Spectrom. 2007, 18, 1582-1590.

21. Iavarone, A. T.; Jurchen, J. C.; Williams, E. R. Effects of Solvent on the Maximum Charge State and Charge State Distribution of Protein Ions
Produced by Electrospray Ionization. J. Am. Soc. Mass Spectrom. 2000, 11, 976-985.

22. Williams, E. R. Proton Transfer Reactivity of Large Multiply Charged Ions. J. Mass Spectrom. 1996, 31, 831-842.

23. Loo, R. R. O.; Smith, R. D. Proton-Transfer Reactions of MultiplyCharged Peptide and Protein Cations and Anions. J. Mass Spectrom. 1995, 30, 339-347.

24. Scalf, M.; Westphall, M. S.; Smith, L. M. Charge Reduction Electrospray Mass Spectrometry. Anal. Chem. 2000, 72, 52-60.

25. Stephenson, J. L.; McLuckey, S. A. Charge Manipulation for Improved Mass Determination of High-Mass Species and Mixture Components by Electrospray Mass Spectrometry. I. Mass Spectrom. 1998, 33, 664-672.

26. Iavarone, A. T.; Jurchen, J. C.; Williams, E. R. Supercharged Protein and Peptide Ions Formed by Electrospray Ionization. Anal. Chem. 2001, 73, 1455-1460.

27. Iavarone, A. T.; Williams, E. R. Supercharging in Electrospray Ionization: Effects on Signal and Charge. Int. J. Mass Spectrom. 2002, 219, 63-72.

28. Sze, S. K.; Ge, Y.; Oh, H.; McLafferty, F. W. Top-Down Mass Spectrometry of a 29-kDa Protein for Characterization of Any Post-Translational Modification to within One Residue. Proc. Natl. Acad. Sci. U.S.A. 2002, 99, 1774-1779.

29. Iavarone, A. T.; Williams, E. R. Collisionally Activated Dissociation of Supercharged Proteins Formed by Electrospray Ionization. Anal. Chem. 2003, 75, 4525-4533.

30. Davies, N. W.; Wiese, M. D.; Browne, S. G. A. Characterization of Major Peptides in 'Jack Jumper' Ant Venom by Mass Spectrometry. Toxicon 2004, 43, 173-183.

31. Kjeldsen, F.; Giessing, A. M. B.; Ingrell, C. R.; Jensen, O. N. Peptide Sequencing and Characterization of Post-Translational Modifications by Enhanced Ion-Charging and Liquid Chromatography Electron-Transfer Dissociation Tandem Mass Spectrometry. Anal. Chem. 2007, 79, 92439252

32. Madsen, J. A.; Brodbelt, J. S. Comparison of Infrared Multiphoton Dissociation and Collision-Induced Dissociation of Supercharged Peptides in Ion Traps. J. Am. Soc. Mass Spectrom. 2009, 20, 349-358.

33. Grimm, R. L.; Beauchamp, J. L. Evaporation and Discharge Dynamics of Highly Charged Multicomponent Droplets Generated by Electrospray Ionization. J. Phys. Chem. A 2010, 114, 1411-1419.

34. Sterling, H. J.; Williams, E. R. Origin of Supercharging in Electrospray Ionization of Noncovalent Complexes from Aqueous Solution. J. Am. Soc. Mass Spectrom. 2009, 20, 1933-1943.

35. Lord Rayleigh. Phils. Mag. 1882, 14, 184-186.

36. Dole, M.; Mack, L. L.; Hines, R. L. Molecular Beams of Macroions. J. Chem. Phys. 1968, 49, 2240-2249.

37. Iribarne, J. V.; Thomson, B. A. Evaporation of Small Ions from Charged Droplets. J. Chem. Phys. 1976, 64, 2287-2294.

38. CRC Handbook of Chemistry and Physics. In [Online] 89th ed.; D. R Lide, Ed. 2008-2009.

39. Scherrenberg, R.; Coussens, B.; van Vliet, P.; Edouard, G.; Brackman, J. de Brabander, E.; Mortensen, K. The Molecular Characteristics of Poly(Propyleneimine) Dendrimers as Studied with Small-Angle Neutron Scattering, Viscosimetry, and Molecular Dynamics. Macromolecules 1998, 31, 456-461.

40. Samalikova, M.; Grandori, R. Protein Charge-State Distributions in Electrospray-Ionization Mass Spectrometry Do Not Appear to be Limited by the Surface Tension of the Solvent. J. Am. Chem. Soc. 2003, 125, 13352-13353.

41. Samalikova, M.; Grandori, R. Testing the Role of Solvent Surface Tension in Protein Ionization by Electrospray. J. Mass Spectrom. 2005, 40, 503-510.

42. Samalikova, M.; Matecko, I.; Muller, N.; Grandori, R. Interpreting Conformational Effects in Protein Nano-ESI-MS Spectra. Anal. Bioanal. Chem. 2004, 378, 1112-1123.

43. Lomeli, S. H.; Peng, I. X.; Yin, S.; Loo, R. R. O.; Loo, J. A. New Reagents for Increasing ESI Multiple Charging of Proteins and Protein Complexes. J. Am. Soc. Mass Spectrom. 2010, 21, 127-131.

44. Lomeli, S. H.; Yin, S.; Loo, R. R. O.; Loo, J. A. Increasing Charge While Preserving Noncovalent Protein Complexes for ESI-MS. J. Am. Soc. Mass Spectrom. 2009, 20, 593-596.

45. Clemmer, D. E.; Jarrold, M. F. Ion Mobility Measurements and Their Applications to Clusters and Biomolecules. J. Mass Spectrom. 1997, 32, 577-592.

46. Wyttenbach, T.; Bowers, M. T. In Modern Mass Spectrometry; Vol. 225; Springer-Verlag: Berlin, 2003; p. 207-232.

47. Kanu, A. B.; Dwivedi, P.; Tam, M.; Matz, L.; Hill, H. H. Ion MobilityMass Spectrometry. J. Mass Spectrom. 2008, 43, 1-22.

48. Giles, K.; Pringle, S. D.; Worthington, K. R.; Little, D.; Wildgoose, J. L.; Bateman, R. H. Applications of a Traveling Wave-Based RadioFrequency Only Stacked Ring Ion Guide. Rapid Commun. Mass Spectrom. 2004, 18, 2401-2414.

49. Giles, K.; Williams, J. P.; Pringle, S. D.; Wildgoose, J. L.; Slade, S. E. Thalassinos, K.; Bateman, R. H.; Bowers, M. T.; Scrivens, J. H. An Investigation of the Mobility Separation of Some Peptide and Protein Ions Using a New Hybrid Quadrupole/Traveling Wave IMS/oa-TOF Instrument. Int. J. Mass Spectrom. 2007, 261, 1-12.

50. Ruotolo, B. T.; Giles, K.; Campuzano, I.; Sandercock, A. M.; Bateman, R. H.; Robinson, C. V. Evidence for Macromolecular Protein Rings in the Absence of Bulk Water. Science 2005, 310, 1658-1661.

51. Ruotolo, B. T.; Hyung, S. J.; Robinson, P. M.; Giles, K.; Bateman, R. H. Robinson, C. V. Ion Mobility-Mass Spectrometry Reveals Long-Lived, 
Unfolded Intermediates in the Dissociation of Protein Complexes. Angew. Chem. Int. Ed. 2007, 46, 8001-8004.

52. Lorenzen, K.; Olia, A. S.; Uetrecht, C.; Cingolani, G.; Heck, A. J. R. Determination of Stoichiometry and Conformational Changes in the First Step of the P22 Tail Assembly. J. Mol. Biol. 2008, 379, 385-396.

53. Scarff, C. A.; Patel, V. J.; Thalassinos, K.; Scrivens, J. H. Probing Hemoglobin Structure by Means of Traveling-Wave Ion Mobility Mass Spectrometry. J. Am. Soc. Mass Spectrom. 2009, 20, 625-631.

54. Hopper, J. T. S.; Oldham, N. J. Collision Induced Unfolding of Protein Ions in the Gas Phase Studied by Ion Mobility-Mass Spectrometry: The Effect of Ligand Binding on Conformational Stability. J. Am. Soc. Mass Spectrom. 2009, 20, 1851-1858.

55. Shelimov, K. B.; Clemmer, D. E.; Hudgins, R. R.; Jarrold, M. F. Protein Structure in Vacuo: Gas-Phase Confirmations of BPTI and Cytochrome c. J. Am. Chem. Soc. 1997, 119, 2240-2248.

56. Shvartsburg, A. A.; Smith, R. D. Fundamentals of Traveling Wave Ion Mobility Spectrometry. Anal. Chem. 2008, 80, 9689-9699.

57. Shelimov, K. B.; Jarrold, M. F. Conformations, Unfolding, and Refolding of Apomyoglobin in Vacuum: An Activation Barrier for Gas-Phase Protein Folding. J. Am. Chem. Soc. 1997, 119, 2987-2994.

58. Van Holde, K. E.; Johnson, W. C.; Ho, P. Principles of Physical Biochemistry. Prentice-Hall, Inc.: Upper Saddle River, NJ, 1998; p. 434.

59. Chanthai, S.; Ogawa, M.; Tamiya, T.; Tsuchiya, T. Studies on Thermal Denaturation of Fish Apomyoglobins Using Differential Scanning Calorimetry, Circular Dichroism, and Fluorescence. Fisheries Sci. 1996, 62, 933-937.

60. Awad, E. S.; Deranleau, D. A. Thermal Denaturation of Myoglobin. I. Kinetic Resolution of Reaction Mechanism. Biochemistry 1968, 7, 17911795.

61. Konermann, L.; Douglas, D. J. Unfolding of Proteins Monitored by Electrospray Ionization Mass Spectrometry: A Comparison of Positive and Negative Ion Modes. I. Am. Soc. Mass Spectrom. 1998, 9, 1248-1254.

62. Kelly, M. A.; Vestling, M. M.; Fenselau, C. C.; Smith, P. B. Electrospray Analysis of Proteins-a Comparison of Positive-Ion and Negative-Ion Mass-Spectra at High and Low pH. Org. Mass Spectrom. 1992, 27, 1143-1147.

63. Sterling, H. J.; Williams, E. R. Proceedings of the 58th ASMS Conference on Mass Spectrometry and Allied Topics; Salt Lake City, UT, May, 2010.

64. Chanthai, S.; Ogawa, M.; Tamiya, T.; Tsuchiya, T. Studies on Thermal Denaturation Profiles of Holo- and Reconstituted Myoglobins from Bonito and Sperm Whale. Fisheries Sci. 1998, 64, 411-414.

65. Pflumm, M.; Luchins, J.; Beychok, S. Stopped-Flow Circular-Dichroism. Methods Enzymol. 1986, 130, 519-534.

66. Chanthai, S.; Ogawa, M.; Tamiya, T.; Tsuchiya, T. Studies on Thermal Denaturation of Fish Myoglobins Using Differential Scanning Calorim- etry, Circular Dichroism, and Tryptophan Fluorescence. Fisheries Sci. 1996, 62, 927-932.

67. Giacometti, G. M.; Antonini, E.; Brunori, M. Kinetics of Reversible Protein Denaturation - Study on Aplysia Myoglobin. Biophys. Chem. $1979,10,119-127$.

68. Abbruzzetti, S.; Sottini, S.; Viappiani, C.; Corrie, J. E. T. Acid-Induced Unfolding of Myoglobin Triggered by a Laser $\mathrm{pH}$ Jump Method. Photochem. Photobiol. Sci. 2006, 5, 621-628.

69. Shen, L. L.; Hermans, J. Kinetics of Conformation Change of SpermWhale Myoglobin . 1. Folding and Unfolding of Metmyoglobin Following $\mathrm{pH}$ Jump. Biochemistry 1972, 11, 1836-1841.

70. Goodman, J. M.; Kirby, P. D.; Haustedt, L. O. Some Calculations for Organic Chemists: Boiling Point Variation, Boltzmann Factors and the Eyring Equation. Tetrahedron Lett. 2000, 41, 9879-9882.

71. Benkestock, K.; Sundqvist, G.; Edlund, P. O.; Roeraade, J. Influence of Droplet Size, Capillary-Cone Distance and Selected Instrumental Parameters for the Analysis of Noncovalent Protein-Ligand Complexes by Nano-Electrospray Ionization Mass Spectrometry. J. Mass Spectrom. 2004, 39, 1059-1067.

72. Charlebois, J. P.; Patrie, S. M.; Kelleher, N. L. Electron Capture Dissociation and C-13, N-15 Depletion for Deuterium Localization in Intact Proteins after Solution-Phase Exchange. Anal. Chem. 2003, 75, 3263-3266.

73. Pan, J.; Han, J.; Borchers, C. H.; Konermann, L. Electron Capture Dissociation of Electrosprayed Protein Ions for Spatially Resolved Hydrogen Exchange Measurements. J. Am. Chem. Soc. 2008, 130, $11574-$ 11575.

74. Rand, K. D.; Adams, C. M.; Zubarev, R. A.; Jørgensen, T. J. D. Electron Capture Dissociation Proceeds with a Low Degree of Intramolecular Migration of Peptide Amide Hydrogens. J. Am. Chem. Soc. 2008, 130 1341-1349.

75. Pan, J. X.; Han, J.; Borchers, C. H.; Konermann, L. Hydrogen/Deuterium Exchange Mass Spectrometry with Top-Down Electron Capture Dissociation for Characterizing Structural Transitions of a $17 \mathrm{kDa}$ Protein. J. Am. Chem. Soc. 2009, 131, 12801-12808.

76. Zehl, M.; Rand, K. D.; Jensen, O. N.; Jorgensen, T. J. D. Electron Transfer Dissociation Facilitates the Measurement of Deuterium Incorporation into Selectively Labeled Peptides with Single Residue Resolution. J. Am. Chem. Soc. 2008, 130, 17453-17459.

77. Abzalimov, R. R.; Kaplan, D. A.; Easterling, M. L.; Kaltashov, I. A Protein Conformations Can Be Probed in Top-Down HDX MS Experiments Utilizing Electron Transfer Dissociation of Protein Ions without Hydrogen Scrambling. J. Am. Soc. Mass Spectrom. 2009, 20, 1514-1517.

78. Rand, K. D.; Zehl, M.; Jensen, O. N.; Jorgensen, T. J. D. Protein Hydrogen Exchange Measured at Single-Residue Resolution by Electron Transfer Dissociation Mass Spectrometry. Anal. Chem. 2009, 81 5577-5584. 